\title{
Perbandingan Fastethernet, Gigabitethernet dan Serial dalam Jaringan Berbasis Routing Protokol EIGRP
}

\section{Conference Paper · November 2015}

CITATIONS

0

2 authors:

Oris Krianto Sulaiman

Universitas Islam Sumatera Utara

7 PUBLICATIONS 1 CITATION

SEE PROFILE
READS

28

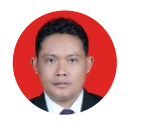

Adi Widarma

State University of Medan

4 PUBLICATIONS 0 CITATIONS

SEE PROFILE

Some of the authors of this publication are also working on these related projects: 


\title{
PERBANDINGAN FASTETHERNET, GIGABITETHERNET DAN SERIAL DALAM JARINGAN BERBASIS ROUTING PROTOKOL EIGRP
}

\author{
Oris krianto sulaiman, Adi widarma \\ Universitas Negeri Medan (UNIMED) \\ Jalan Willem Iskandar Pasar V Medan Estate, Kec.Medan Tembung, Medan, Sumatera Utara 20221 \\ e-mail: oris.ks@unimed.ac.id
}

\begin{abstract}
Abstrak - Perkembangan teknologi dalam jaringan komputer lambat laun semakin pesat seiring dengan meningkatnya kebutuhan akan akses jaringan yang efisien, stabil dan cepat. Salah satu faktor yang mempengaruhi kecepatan dalam jaringan adalah dengan menggunakan teknologi ethernet dan serial dimana masing-masing teknologi ini memiliki karakteristik tersendiri dalam meningkatkan kinerja dalam jaringan. Teknologi ini didukung juga dengan perancangan jaringan yang baik. Dalam jaringan skala besar sangat dibutuhkan kemampuan yang tinggi untuk meningkatkan kinerja jaringan, routing protokol EIGRP memungkinkan peningkatan kinerja jaringan secara efektif dimana salah satunya untuk teknologi ethernet dan serial. Pemilihan teknologi Ethernet dan serial dalam routing protokol EIGRP akan sangat membantu dalam meningkatkan kinerja jaringan, dengan perhitungan dari metrik EIGRP untuk membandingkan teknologi mana yang baik dalam routing protokol EIGRP.
\end{abstract}

Kata kunci: Ethernet, Serial, Routig protokol EIGRP, metrik

\begin{abstract}
Technological developments in the computer network gradually grew rapidly along with the increasing demand for network access that is efficient, stable and fast. One of the factors that affect the speed of the network is to use ethernet and a serial technology in which each of these technologies has its own characteristics to improve performance in the network. This technology is supported by a good network design. In large-scale networks is needed a high ability to improve network performance, EIGRP routing protocol enables improved network performance effectively where one of them for ethernet and serial technologies. Selection of Ethernet and serial technologies within EIGRP routing protocol would greatly assist in improving the performance of the network, with the calculation of EIGRP metric to compare which technology is better in the EIGRP routing protocol.
\end{abstract}

Keywords: Ethernet, Serial, Routig protokol EIGRP, metric

\section{Pendahuluan}

Kebutuhan akan jaringan komputer semakin bertambah penting, baik dalam pendidikan, pekerjaan maupun dalam sebuah permainan, jaringan komputer memiliki salah satu teknologi untuk meningkatkan kinerjanya yaitu teknologi Ethernet dan serial, teknologi Ethernet sendiri dibagi menjadi beberapa dan yang saat ini paling banyak digunakan adalah fastethernet dan gigabitethernet.

Teknologi ini juga digunakan dalam jaringan skala besar, dalam jaringan skala besar digunakan router untuk membagi network yang berbeda, selain itu untuk meningkatkan performa jaringan digunakanlah routing protokol agar dapat melakukan pemilihan jalur terbaik yang dilalui dari sumber ke tujuan. Salah satu routing protokol yang handal adalah EIGRP, dengan menggunakan routing protokol EIGRP bagaimana di dapat perhitungan yang baik dari metric EIGRP pada teknologi ethernet dan serial.

\section{A. Ethernet}

Ethernet merupakan teknologi jaringan untuk pengiriman data, ethernet hanya mempunyai kecepatan $10 \mathrm{Mbit} /$ detik, spesifikasi ini telah di setujui oleh IEEE 802.3,standarisasi yang digunakan ethernet adalah 10Base2, 10Base5, 10BaseF dan 10 BaseT.
Perkembangan kecepatan ethernet berlanjut menjadi $100 \mathrm{Mbit} /$ detik yang disebut dengan fastethernet. Fastethernet telah disetujuti oleh IEEE802.3u dengan standarisasi yang digunakan adalah 100BaseFX, 100BaseT, 100BaseT4, 100BaseTX.

Fastethernet merupakan teknologi jaringan yang paling banyak digunakan saat ini, namun perkembangan ethernet tidak berhenti disini ,perkembangan selanjutnya dari teknologi ini adalah gigabitethernet yang mempunyai kecepatan hingga $1000 \mathrm{Mbit} /$ detik yang disetujui IEEE $802.3 \mathrm{z}$, standarisasi yang digunakan adalah 1000BaseCX, 1000BaseLX ,1000BaseSX dan 1000BaseT.

Ethernet menentukan standar untuk interface elektrik, tipe kabel, konfigurasi konektor, dan sebagainya, serta bagaimana mengirim sebuah paket ethernet dari satu mesin ke mesin lain pada kabel yang sama atau pada segmen yang sama, ethernet menggunakan alamat yang disebut dengan MAC address (Media Access Control atau Medium Access Control) atau alamat hardware.

Ethernet mendukung paket-paket paket-paket broadcast yang diterima dan diproses oleh setiap mesin pada segmen ethernet tersebut. 


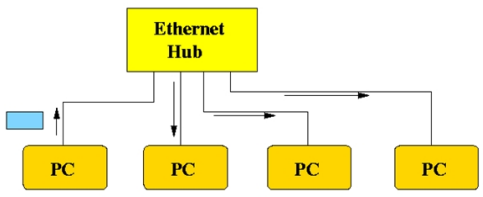

Gambar 1. Broadcast ethernet

\section{B. Komunikasi Serial}

Merupakan komunikasi data yang dilakukan untuk remote suatu perangkat tetapi juga digunakan dalam cisco wan interface, di cisco default bandwith untuk serial adalah 1544 Kbit, koneksi dari serial ini mempunyai dua sisi yang berbeda yaitu

- DTE (Data Terminal Equipment)

- DCE (Data Circuit-terminating Equipment)

DTE adalah Perangkat yang paling akhir dari penerima koneksi dan DCE adalah perangkat paling akhir dari pemberi koneksi.

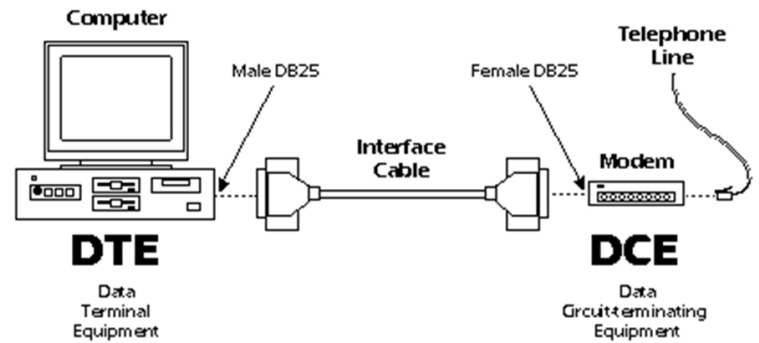

Gambar 2.Komunikasi serial DTE dan DCE

\section{Routing}

Proses menghubungkan 2 atau lebih network yang berbeda dengan hardware yang bernama router, Router berfungsi untuk mengirimkan paket data dari satu network ke network lain sekaligus menentukan jalur terbaik (best path) untuk mencapai network tujuan, untuk menjalankan fungsi tersebut router menggunakan tebel yang disebut table routing dimana table tersebut berisikan informasi keberadaan beberapa network, baik yang terhubung langsung (directly connected network) maupun network yang tidak terhubung langsung (remote network).

Proses routing ini juga menggunakan protokol-protokol routing untuk menentukan best path (jalur terbaik) dengan menggunakan metric sebagai nilai untuk mencari jalur terbaik, beberapa jenis protokol routing :

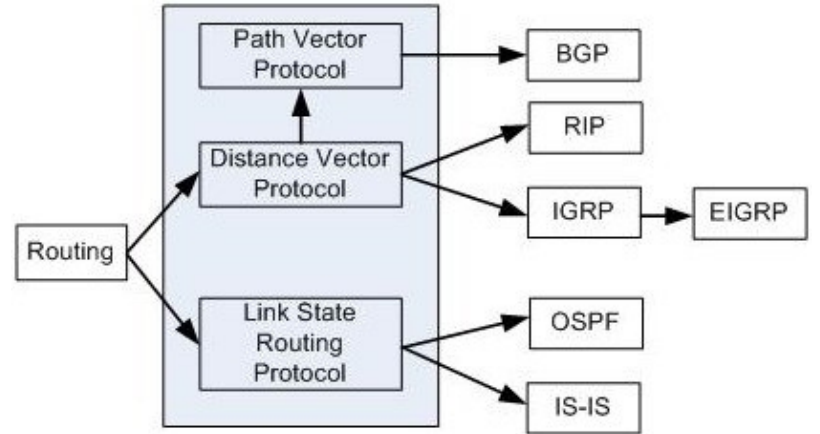

Gambar 3. Jenis-jenis protokol routing

Tiap-tiap protokol routing mempunyai metric yang berbeda contoh : RIP menggunakan hop sebagai metric untuk mencapai tujuan, OSPF menggunakan cost sebagai metric untuk mencapai tujuan, sementara EIGRP menggunakan metric :

$=[(1 *$ Bandwidth $+0 *$ bandwidth $/ 256-$ Load +1 *Delay) $* 0 / 0+$ Reliability $* 256$

$=[$ (Bandwidth $+0+$ Delay $) * 0] * 256$

$=($ Bandwidth + Delay $) * 256$ atau $256 *$ (Bandwidth + Delay)

\section{Enhanced Interior Gateway Routing Protocol (EIGRP)}

EIGRP (Enhanced Interior Gateway Routing Protocol) adalah routing protocol yang hanya di adopsi oleh router Cisco atau sering disebut sebagai proprietary protocol pada Cisco. Dimana EIGRP ini hanya 219the digunakan 219thern router Cisco saja dan routing ini tidak didukung dalam jenis router yang lain.

Karakteristik dari routing protocol EIGRP

$>$ Distance Vector Routing Protocol

$>$ Metrics yang digunakan sama dengan IGRP

- Bandwidth (used by default)

- Delay (used by default)

- Reliability

- Load

> Termasuk protokol routing distance vector tingkat lanjut (Advanced distance vector).

$>$ Waktu convergence yang cepat.

$>$ Mendukung VLSM

> Partial updates, Tidak seperti RIP yang selalu mengirimkan keseluruhan 219ther routing dalam pesan Update, EIGRP menggunakan partial updates atau triggered update yang berarti hanya mengirimkan update jika terjadi perubahan pada network

$>$ Mendukung multiple protokol network

> Multicast dan unicast, EIGRP saling berkomunikasi dengan tetangga (neighbor) nya secara multicast (224.0.0.10) dan tidak membroadcastnya.

> Manual summarization, EIGRP dapat melakukan summarization dimana saja.

$>$ EIGRP menggunakan algoritma DUAL (Diffusing Update Algorithm) sebagai mesin utama yang menjalankan lingkungan EIGRP.

\section{Metode Penelitian}

Metode yang digunakan dalam perbandingan ini adalah dengan menggunakan routing protokol EIGRP didasarkan pada simulasi perancangan jaringan yang menggunakan 219thernet dan komunikasi serial.

Penelitian dilakukan secara simulasi dengan menggunakan cisco packet tracer (CPT) dengan topologi perancangan sebagai berikut : 


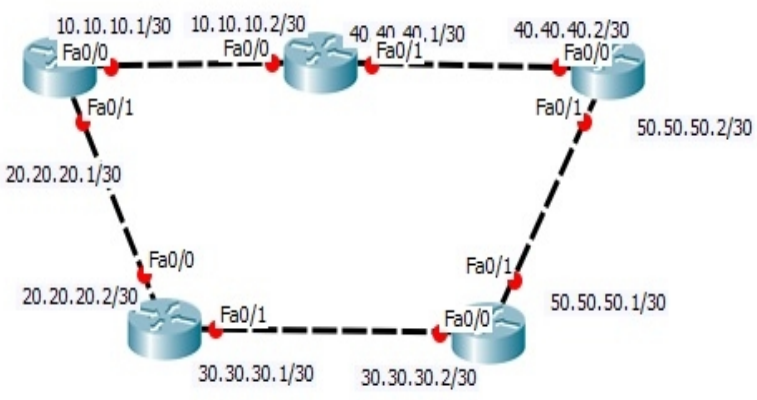

Gambar 4. Rancangan topologi

Terdapat 5 router yang akan di jadikan perbandingan fastethernet, gigethernet dan serial, daftar ip pada setiap router adalah :

$>10.10 .10 .0 / 30$

$>\quad 20.20 .20 .0 / 30$

$>\quad 30.30 .30 .0 / 30$

$>\quad 40.40 .40 .0 / 30$

$>\quad 50.50 .50 .0 / 30$

Semua router harus menggunakan protocol routing EIGRP yang mempunyai perhitungan

$=[(1 *$ Bandwidth $+0 *$ bandwidth $/ 256-$ Load +1 *Delay) * 0 / $0+$ Reliability] $* 256$

$=[($ Bandwidth $+0+$ Delay $) * 0] * 256$

$=($ Bandwidth + Delay $) * 256$ atau $256 *$ (Bandwidth + Delay)

\section{E. Fastethernet}

Percobaan pertama adalah mencari hasil metric EIGRP dengan menggunakan fastethernet

EIGRP (FASTETHERNET)

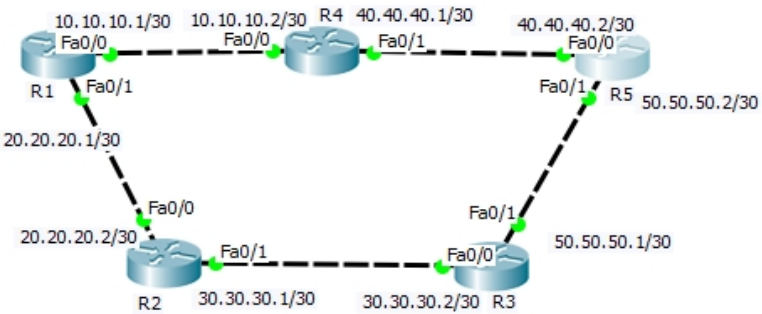

Gambar 5. EIGRP (Fastethernet)

EIGRP akan memproses jalur dengan algoritma DUAL, jika sudah terkoneksi maka akan ada pemberitahuan telah terhubung, contoh pada router 1 yang telah mengaktifkan EIGRP

R1\#

\%DUAL-5-NBRCHANGE: IP-EIGRP 10: Neighbor 10.10.10.2 (FastEthernet0/0) is up: new adjacency \%DUAL-5-NBRCHANGE: IP-EIGRP 10: Neighbor 20.20.20.2 (FastEthernet0/1) is up: new adjacency Table routing akan terbentuk setelah semua terhubung dengan routing protokol EIGRP sebagai berikut $\mathrm{R} 1$ \#show ip route

Codes: C - connected, D - EIGRP

10.0.0.0/8 is variably subnetted, 2 subnets, 2 masks

D 10.0.0.0/8 is a summary, 00:11:07, Null0

C $10.10 .10 .0 / 30$ is directly connected, FastEthernet $0 / 0$
20.0.0.0/8 is variably subnetted, 2 subnets, 2 masks

D 20.0.0.0/8 is a summary, 00:11:07, Null0

C 20.20.20.0/30 is directly connected, FastEthernet0/1

D 30.0.0.0/8 [90/30720] via 20.20.20.2, 00:09:01, FastEthernet $0 / 1$

D 40.0.0.0/8 [90/30720] via 10.10.10.2, 00:09:54, FastEthernet $0 / 0$

D50.0.0.0/8 [90/33280] via $10.10 .10 .2, \quad 00: 08: 25$, FastEthernet $0 / 0$

[90/33280] via 20.20.20.2, 00:07:24, FastEthernet0/1

Perhitungan EIGRP

[90/30720] merupakan [AD/Metric]

AD merupakan administration distance yaitu nilai kepercayaan pemilihan routing protocol, semakain rendah $\mathrm{AD}$ maka routing protokol itu yang akan dipilih.

Dengan menggunakan fastethernet terlihat ada 2 metric yang berbeda

Jalur dengan metric 30720 dan 33280

Perhitungan metric :

Untuk melakukan perhitungan, terlebih dahulu memeriksa berapa bandwidth dan delay fastethernet

R1\#show interfaces fastEthernet $0 / 0$

MTU 1500 bytes, BW 100000 Kbit, DLY 100 usec,

reliability $255 / 255$, txload $1 / 255$, rxload $1 / 255$

Fastethernet memiliki bandwidth 100000 Kbit dan delay $100 \mathrm{sec}$

Untuk metric 30720

Hitung Bandwidth $=\left(10^{7} /\right.$ bandwidth terkecil dari dari fa, serial, dll dalam kilobit)

Hitung Bandwidth $=(10.000 .000 / 100.000)=\mathbf{1 0 0}$

Hitung Delay $=(($ delay dari R1 ke R2 + R2 ke R3 $) / 10)$

Hitung Delay $=((100+100) / 10)=\mathbf{2 0}$

Metric $=256 *(100+20)=\mathbf{3 0 7 2 0}$

Untuk metric 33280

Hitung Bandwidth $=\left(10^{7} /\right.$ bandwidth terkecil dari dari fa, serial, dll dalam kilobit)

Hitung Bandwidth $=(10.000 .000 / 100.000)=\mathbf{1 0 0}$

Hitung Delay $=(($ delay dari R1 ke R2 + R2 ke R3 + R3 ke R5) /10)

Hitung Delay $=((100+100+100) / 10)=\mathbf{3 0}$

Metric $=256 *(100+30)=\mathbf{3 3 2 8 0}$

\section{B. Gigabitethernet}

Pada percobaan selanjutnya adalah mencari hasil metric EIGRP menggunakan gigabitethernet

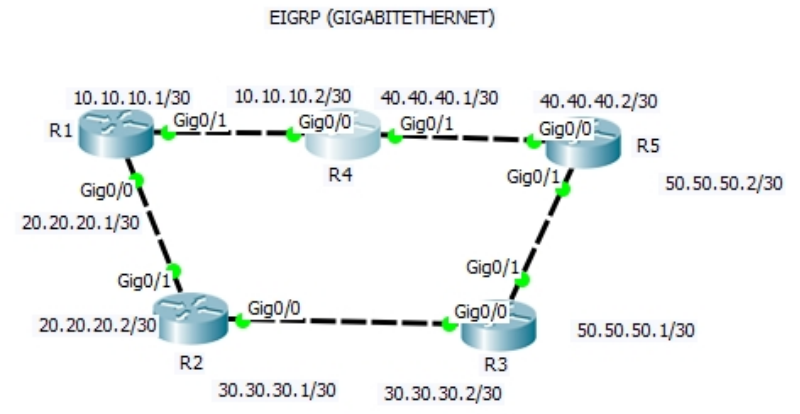

Gambar 6. EIGRP (Gigabitethernet) 
R1\#show ip route

D 30.30.30.0/30 [90/3072] via 20.20.20.2, 00:03:16,

GigabitEthernet $0 / 0$

40.0.0.0/30 is subnetted, 1 subnets

D 40.40.40.0/30 [90/3072] via 10.10.10.2, 00:02:26,

GigabitEthernet $0 / 1$

50.0.0.0/30 is subnetted, 1 subnets

D 50.50.50.0/30 [90/3328] via 10.10.10.2, 00:01:41, GigabitEthernet $0 / 1$

[90/3328] via 20.20.20.2, 00:00:15,

GigabitEthernet $0 / 0$

Terlihat bahwa mempunya 2 metric yang berbeda

Bandwidth dan delay dari gigabitethernet adalah sebagai berikut :

R1\#show interfaces gigabitEthernet $0 / 0$

GigabitEthernet $0 / 0$ is up, line protocol is up (connected)

Hardware is CN Gigabit Ethernet, address is 0001.63b3.4201 (bia 0001.63b3.4201)

Internet address is 20.20.20.1/30

MTU 1500 bytes, BW 1000000 Kbit, DLY 10 usec,

Untuk metric 3072

Hitung Bandwidth $=\left(10^{7} /\right.$ bandwidth terkecil dari dari fa, serial, dll dalam kilobit)

Hitung Bandwidth $=(10.000 .000 / 1.000 .000)=\mathbf{1 0}$

Hitung Delay $=(($ delay dari R1 ke R2 + R2 ke R3) /10 $)$

Hitung Delay $=((10+10) / 10)=\mathbf{2}$

Metric $=256 *(10+2)=\mathbf{3 0 7 2}$

Untuk metric 3328

Hitung Bandwidth $=\left(10^{7} /\right.$ bandwidth terkecil dari dari fa, serial, dll dalam kilobit)

Hitung Bandwidth $=(10.000 .000 / 1.000 .000)=\mathbf{1 0}$

Hitung Delay $=(($ delay dari R1 ke R2 + R2 ke R3 + R3 ke R5) /10)

Hitung Delay $=((10+10+10) / 10)=\mathbf{3}$

Metric $=256 *(10+3)=\mathbf{3 3 2 8}$

C. Serial

Hasil metric EIGRP menggunakan serial port:

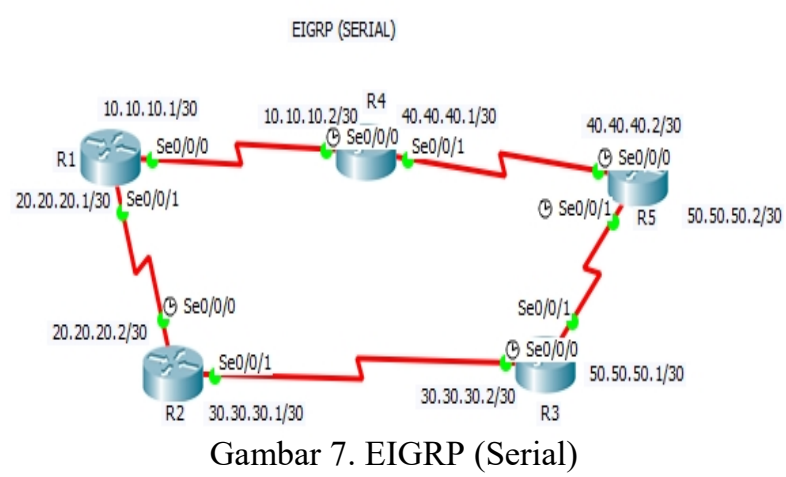

Df R1\#show ip route

10.0.0.0/8 is variably subnetted, 2 subnets, 2 masks

C $\quad 10.10 .10 .0 / 30$ is directly connected, Serial0/0/0

L $\quad 10.10 .10 .1 / 32$ is directly connected, Serial0/0/0
20.0.0.0/8 is variably subnetted, 2 subnets, 2 masks

C $\quad 20.20 .20 .0 / 30$ is directly connected, Serial0/0/1

L $\quad 20.20 .20 .1 / 32$ is directly connected, Serial0/0/1 $30.0 .0 .0 / 30$ is subnetted, 1 subnets

D $30.30 .30 .0 / 30[90 / 2681856]$ via 20.20.20.2,

00:04:55, Serial0/0/1

$40.0 .0 .0 / 30$ is subnetted, 1 subnets

D $40.40 .40 .0 / 30[90 / 2681856]$ via 10.10 .10 .2 ,

00:04:31, Serial0/0/0

$50.0 .0 .0 / 30$ is subnetted, 1 subnets

D $\quad 50.50 .50 .0 / 30[90 / 3193856]$ via 20.20 .20 .2 ,

00:04:07, Serial0/0/1

[90/3193856] via 10.10.10.2, 00:03:41,

Serial0/0/0.

Bandwidth dan delay dari serial adalah

R1\#show interfaces serial 0/0/0

MTU 1500 bytes, BW 1544 Kbit, DLY 20000 usec

Metric menuju network 40.40.40.0 adalah 2681856

Metric menuju network 50.50.50.0 adalah 3193856

Untuk metric 2681856

Hitung Bandwidth $=\left(10^{7} /\right.$ bandwidth terkecil dari dari fa, serial, dll dalam kilobit)

Hitung Bandwidth $=(10.000 .000 / 1.544)=6476$

Hitung Delay $=(($ delay dari R1 ke R2 + R2 ke R3) /10)

Hitung Delay $=((20000+20000) / 10)=4000$

Metric $=256 *(6476+4000)=\mathbf{2 6 8 1 8 5 6}$

Untuk metric 2681856

Hitung Bandwidth $=\left(10^{7} /\right.$ bandwidth terkecil dari dari fa, serial, dll dalam kilobit)

Hitung Bandwidth $=(10.000 .000 / 1.544)=6476$

Hitung Delay $=(($ delay dari R1 ke R2 + R2 ke R3 + R3 ke R5) /10)

Hitung Delay $=((20000+20000+20000) / 10)=6000$

Metric $=256 *(6476+6000)=3193856$

\section{Hasil dan Pembahasan}

EIGRP (FASTETHERNET GIGABITEIHERNET \& SERIAL)

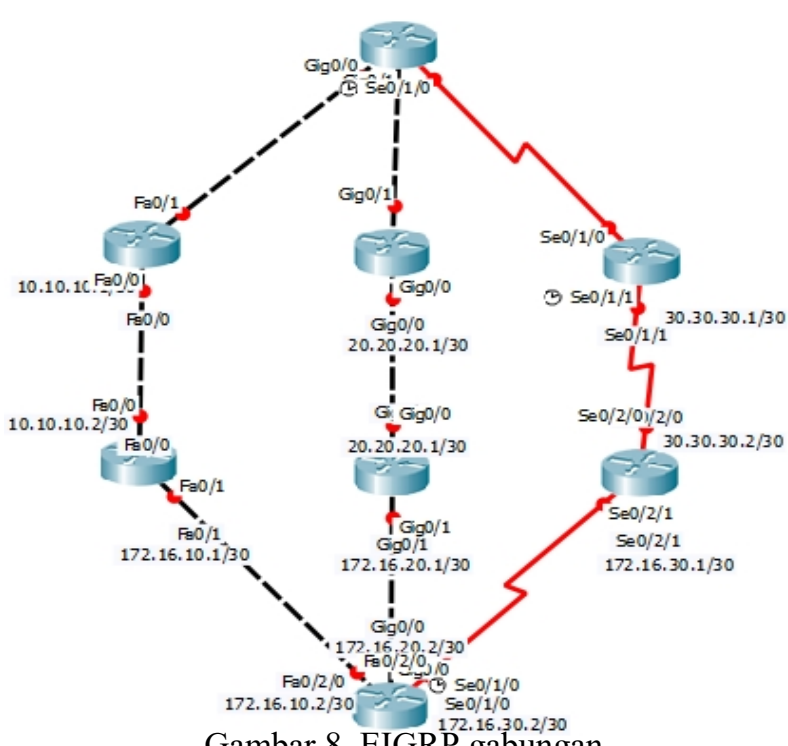

Gambar 8. EIGRP gabungan 
Topologi yang dirancang merupakan implementasi dari semua teknologi yaitu fastethernet, gigabitethernet dan serial.

Fastethernet mempunyai nilai

Hitung Bandwidth $=(107 /$ bandwidth terkecil dari dari

fa, serial, dll dalam kilobit)

Hitung Bandwidth $=(10.000 .000 / 100.000)=100$

Hitung Delay $=(($ delay dari R1 ke R2 + R2 ke R3 + R3

ke R4) /10)

Hitung Delay $=((100+100+100) / 10)=30$

Metric $=256 *(100+30)=33280$

Gigabitethernet mempunyai nilai

Hitung Bandwidth $=(107 /$ bandwidth terkecil dari dari fa, serial, dll dalam kilobit)

Hitung Bandwidth $=(10.000 .000 / 1.000 .000)=10$

Hitung Delay $=(($ delay dari R1 ke R2 + R2 ke R3 + R3 ke R4) /10)

Hitung Delay $=((10+10+10) / 10)=3$

Metric $=256 *(10+3)=3328$

Serial mempunyai nilai

Hitung Bandwidth $=(107 /$ bandwidth terkecil dari dari fa, serial, dll dalam kilobit)

Hitung Bandwidth $=(10.000 .000 / 1.544)=6476$

Hitung Delay $=(($ delay dari R1 ke R2 + R2 ke R3 + R3 ke R4) /10)

Hitung Delay $=((20000+20000+20000) / 10)=6000$

Metric $=256 *(6476+6000)=3193856$

Dalam hal ini routing protokol EIGRP akan memilh jalur terbaik berdasarkan nilai cost terendah yaitu gigabitethernet.

Fastethernet : 33280

Gigabitethernet : 3328

Serial : 3193856

\section{Kesimpulan}

Routing protokol EIGRP memilih jalur terbaik berdasarkan cost metric terendah, dalam perbandingan ini terlihan bahwa jalur gigabitethernet lah yang akan dipilih oleh routing protokol EIGRP. Kedepannya dapat diteliti pengembangan dari perbandingan ini seperti analisis gigabitethernet sebagai jalur terbaik menggunakan routing protokol EIGRP.

\section{Daftar Pustaka}

[1] A. A. Purwanto, "Perancangan dan simulasi jaringan fastethernet dengan menggunakan routing protocol OSPF dan EIGRP”, UI, Jakarta, 2007.

[2] Cisco Syste, "Serial Connectivity Network Modules, USA, 2005.

[3] Jeevan Prasad Adhikari, "Performance Analysis of Protocols RIP \& EIGRP”, International Journal of Innovative Technology and Exploring Engineering (IJITEE), vol-2, pp 107-111, April 2013.
[4] G. Komal, N.C. Barwar "Performance evaluation of EIGRP and OSPF Routing Protocols in Real Time Applications", international Journal of Emerging el Technology in Computer Science (IJETTCS), volume 3, pp. 137-143, February 2014.

[5] S. Jagdeep, Dr. M. Rajiv. "Simulation Based Comparative Study of RIP, OSPF and EIGRP", International Journal of Advanced Research in Computer Science and Software Engineering, volume 3, pp. 285-288, 8 August 2013. 